\title{
LASER SCANNER SURVEY TO CULTURAL HERITAGE CONSERVATION AND RESTORATION
}

\author{
G. Vacca ${ }^{\mathrm{a}} *$, M. Deidda ${ }^{\mathrm{a}}$, A. Dessi ${ }^{\mathrm{a}}$, M. Marras $^{\mathrm{a}}$ \\ ${ }^{a}$ DICAAR, Engineering Faculty, University of Cagliari \\ P.zza D’Armi 09123 Cagliari, Italy \\ (vaccag,mdeidda,monica.marras)@unica.it
}

CIPA, ICOMOS and WG V/2

KEY WORDS: laser scanning, cultural heritage, conservation, surveying, point cloud

\begin{abstract}
The field of Cultural Heritage has inspired, in the course of last few years, an interest more and more important on behalf of scientific community that deals to survey. The idea that knowledge of a site doesn't apply only to its history but must necessarily include its characteristics of position, shape and geometry, is gathering pace.

In Geomatic science the field of cultural heritage benefits to an integrated approach of techniques and different technologies. Every cultural site in fact, is a case in itself, with its own characteristics, problems and specificness.

Current techniques offer opportunity to achieve new ways of representation and visualization of cultural site, with the aim of a better metric description. This techniques are powerful tools for analysis of sites and supports to activity of reconstruction and repair.

Biggest expectations in this field is laser three-dimensional scanning technique; a system which is able to operate in a methodical way in speed of acquisition and in possibility to access data in real time. Documentation and filing of state of a monument or site is essential in case of reconstruction or conservative project.

Possibility to detect very complex geometries with great accuracy allows an in depth study of constructive techniques, making analysis of geometrical details easier which is, with traditional techniques, difficult to achieve.

Biggest problems about use of laser scanner survey are graphic outputs for restorers and architects, in fact they often don't know real potential of this techniques, methodologies and functionalities and they expect traditional outputs such as floor plans, cross sections and front elevation of cultural asset.

Present study is focused on finding a workflow to support activity of study, restoration and conservative project of cultural heritage, extracting automatically (or with a limited manual operation) graphic outputs from laser scanner survey. Some procedure was tested on two case study the Siviller Castle (XV century), situated in Villasor, a city near Cagliari (Sardinia, Italy) and the tower bell of Mores, near Sassari (Sardinia, Italy).

The cultural sites were surveyed with laser scanner Focus 3D by Faro and to process clouds point we were used the JRC 3D Reconstructor software
\end{abstract}

\section{INTRODUCTION}

The field of Cultural Heritage has inspired, in course of last few years, an interest more and more important on behalf of scientific community that deals to survey. Idea that knowledge of a site doesn't apply only to its history but must necessarily include its characteristics of position, shape and geometry, is gathering pace.

In Geomatic science field of cultural heritage benefits to an integrated approach of techniques and different technologies. Every cultural site in fact, is a case in itself, with its own characteristics, problems and specificness. Current techniques offer opportunity to achieve new ways of representation and visualization of cultural site, with the aim of a better metric description. This techniques are powerful tools for analysis of sites and supports activity of reconstruction and repair.

Biggest expectations in this field is laser three-dimensional scanning technique; a system which is able to operate in a methodical way in speed of acquisition and in possibility to access data in real time. Documentation and filing of state of a monument or site is essential in case of reconstruction or conservative project.

Possibility to detect very complex geometries with great accuracy allows an in depth study of constructive techniques, making analysis of geometrical details easier which is, with traditional techniques, difficult to achieve.

Biggest problems in use of survey techniques are graphic outputs for restorers and architects, in fact they often don't know real potential of this techniques, methodologies and functionalities and they expect traditional outputs such as floor plans, sections and front elevation of cultural asset.

Present study is focused on finding a workflow to support activity of study, restoration and conservative project of cultural heritage, extracting automatically (or with a limited manual operation) graphic outputs from laser scanner survey. Procedure was tested on two study cases: the Siviller Castle (XV century), situated in Villasor, a city near Cagliari (Italy) and Mores bell tower (1860), the highest bell tower in Sardinia (Italy).

\footnotetext{
* Corresponding author. This is useful to know for communication with the appropriate person in cases with more than one author.
} 
Issues relating two case studies are very different and choices solutions were adapted to two different surveys. In next part will be presenting surveys carried out and solutions chose.

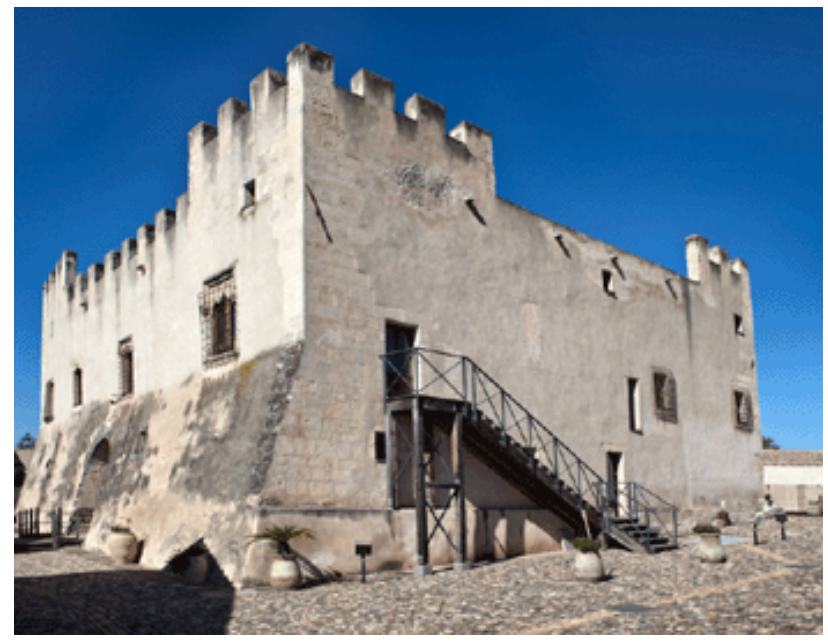

Fig. 1. Sivillier Castle

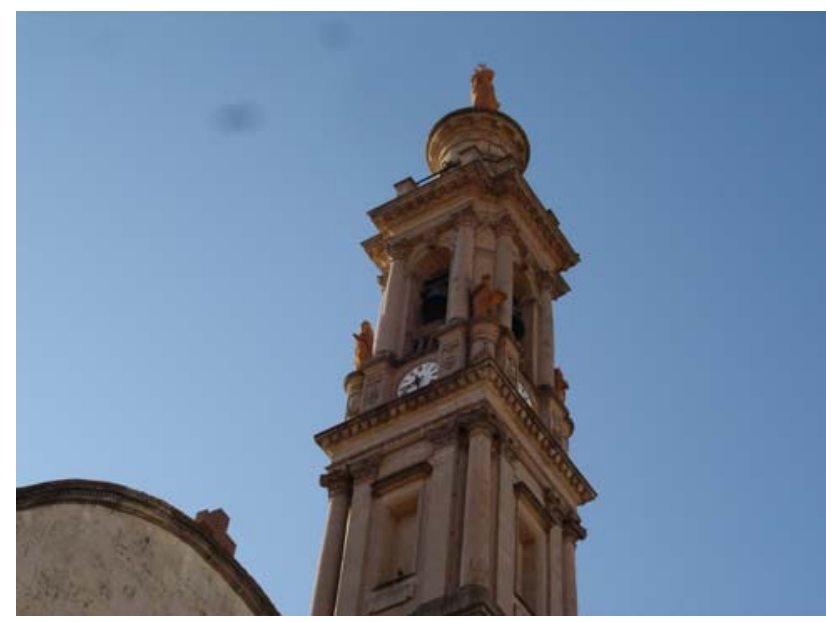

Fig. 2. Mores Tower Bell

For laser scanner survey we used a laser scanner Focus 3D by Faro and delivered in Italy by Cam2.

It's a very versatile and lightweight instrument that allows to perform scans up to $120 \mathrm{~m}$ of distance with high speed point acquisition up to 976.000 points/second.

For management, processing and processing of laser data we were used the JRC 3D Reconstructor Software by Gexcel srl.

Laser scanner surveys have been performed trough some steps :

- Scans planning;

- Scans acquisition;

- Data elaboration;

- Extraction of geometric information;

- Graphic outputs.

\section{LASER SCANNER FOCUS 3D}

A laser scanner survey consist of many scans that cover whole building internal and external surface.
To perform scans was used a laser scan Focus3D by Faro. Instrument was designed to obtain a laser scanner lightweight and with a high potential for documenting internal and external applications for architecture, restoration and industrial. It's a scanner with high-speed and contained size $(24 \mathrm{~cm}$ x20 cm x10 $\mathrm{cm}$ ) and weight (5 kg). It's equipped with a WLAN (WiFi) that allow you to start, to stop, and to download scans also at a distance to site.

Characteristic of this compact instrument is a range from $0.6 \mathrm{~m}$ to $120 \mathrm{~m}$ with an error of linear distance equal $\pm 2 \mathrm{~mm}$ for a distance between scanner and object included in a range from 10 to 25 meters and a noise (standard deviation of the values from the best-fit plan) variable from $0.6 \mathrm{~mm}$ to $10 \mathrm{~m}$ with a $90 \%$ reflectivity and from $2.2 \mathrm{~mm}$ to $25 \mathrm{~m}$ with a $10 \%$ reflectivity. It also has a vertical visual field of $305^{\circ}$ and the horizontal one of $360^{\circ}$. Both horizontal and vertical resolution is $0.009^{\circ}$. Laser scanner Focus $3 \mathrm{D}$ has a scansion speed of $976.000 \mathrm{dot} / \mathrm{sec}$. A colour digital camera with a 70 megapixel resolution is integrated in laser scanner.

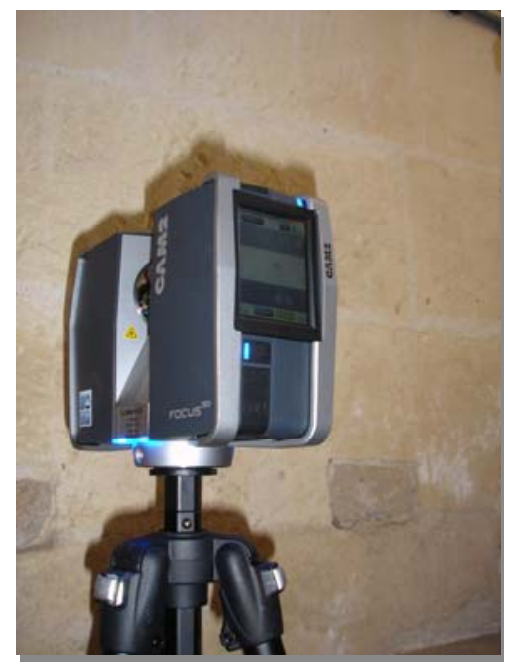

Fig. 3. Faro Focus 3D Laser Scanner

\section{DATA PROCESSING}

To process point clouds we used JRC Reconstructor 2 Software v. 2.8.02.247 of Gexcel srl. This is a software that allows you to perform all steps to obtain 3D model of the scanned object. It's allow extraction of drawings relevant to conservation and restoration.

Point clouds can be used in different ways especially in relation to needs of survey. It can be oriented and projected in order to perform orthogonal projections; can be sectioned with planes selected by operator to carry out traditional sections or to highlight particular aspects as deformations, breaks etc..Finally, point clouds can process to perform 3D surface, especially when it is necessary to emphasize discontinuity of object, in this case point clouds can be transformed into a continuous surface with several processes such as mesh, NURBS, etc.

In particular, steps carry out in our point clouds are: 1.Clean of point clouds: this is made with filtering of noise point clouds mainly due to divergence of laser beam and standard deviation of instrument.

2. Manual delete of points that don't belong to point clouds. 3. Alignment of single scan (or scans registration), is procedure to align and merge single scan in a point clouds according to arbitrary reference system. 
4. Georeferencing of clouds of points in a system of external reference known a priori.

5. Triangulation and performing mesh.

6. Mesh closure and correction of abnormal faces.

7. Extraction vertical and horizontal sections for realization of plans, elevations and sections aimed at creating final product required by architects and restorers. 8. Perform ortophoto.

9. Perform 3D model of site.

The following figures are shown results obtained from processing of points cloud with JRC Reconstructor 2.

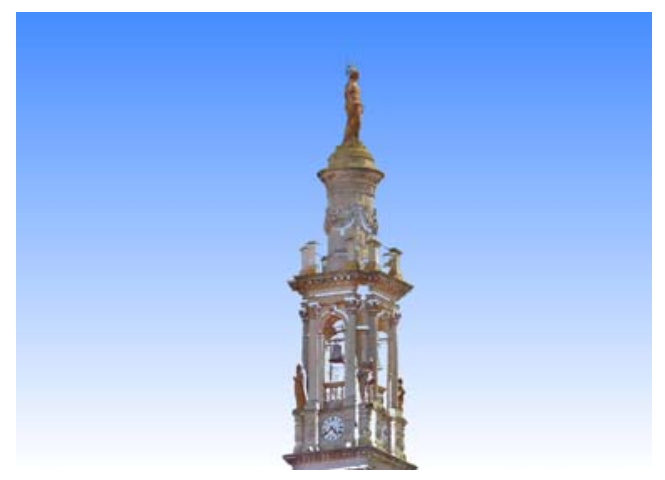

Fig. 4: Point clouds

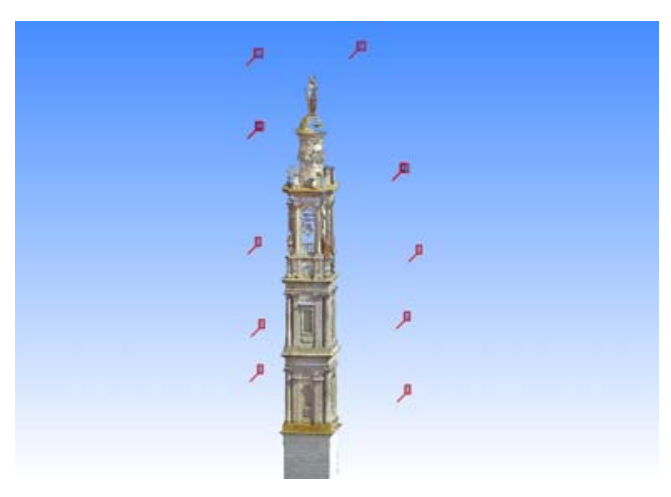

Fig. 5: Points of scans

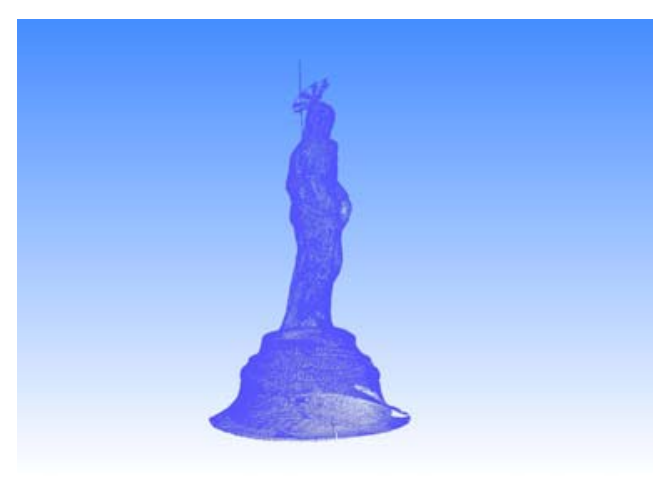

Fig. 6: Statue with contour line

\section{THE SIVILLIER CASTLE}

First case study is the Sivillier Castle (XV c.), architectural heritage of historically important that, now, is used as a library and cultural centre for exhibitions and events. At present the castle is pouring in critical structural conditions, particularly for connecting structure horizontal and vertical.

On 14/09/2011 the castle was declared unsafe by municipal authorities and it was closed to public and employees. Munipality of Villasor has therefore entrusted project of restoration and enhancement of Sivillier Castle to University of Cagliari.

Survey and preparation of drawings for architects and restorers have been assigned to the research group of the Section of Topography of the University of Cagliari. The castle was built in 1415 by Giovanni Siviller and it's located in the historical centre of Villasor (town about $50 \mathrm{~km}$ from Cagliari). The Castle was originally made up of four sides, now retain only three (the fourth side was pulled down in the nineteenth century). The Castle is one of rarest and most significant expressions, in Sardinia, of late Gothic- Aragonese architecture.

After abolition of feuds in Sardinia, the castle was used like a warehouse for food and only in 1991 was awarded to municipal heritage.

This castle has a structure that is not particularly complex in its geometry, except for the fact that its walls are not vertical and its floors are not perfectly horizontal. The castle has a horseshoe-shaped: a passage that leads to an internal court divides ground floor in two parts. Both first and second floor have adjoining rooms divided by partition walls. The Siviller castle was surveyed using Focus 3D, most recent laser scanner produced by Faro.

Survey was divided in following steps:

- Scans planning;

- Scans acquisition;

- Data elaboration;

- Extraction of geometric information;

- Graphic outputs.

Requirements were for an accuracy sufficient for the 1:50 scale. For this scale, considering an graphic error equal to $0.4 \mathrm{~mm}$, the requested accuracy is $+/-2 \mathrm{~cm}$.

In order to have a complete survey of the castle without empty and a good number of overlapping scans (at least $30 \%$ of them), we made 61 scans with a resolution of $7 \mathrm{~mm}$. Scans were made on ground except for 3 that were acquired by a lifting platform in order to survey the roof.

We used the JRC 3D Reconstructor software for both data processing and extraction of the final results.

Aim of laser scanner survey of Sivillier Castle was not only to perform all graphic documentation to support project as plans, elevations and sections but also to study geometric characteristics of vertical and horizontal structures.

From the castle model we extracted following graphic outputs: - Horizontal sections at different heights from the floor (one every $50 \mathrm{~cm}$ ) for the ground, first and under roof floors;

- Vertical sections;

- Internal and external elevations of the castle;

- Orthophoto of both internal and external walls (with GSD 2 $\mathrm{cm})$.

At present all graphic outputs were submitted to manual editing of an expert designer, for completing them and in order to make them understandable by restorers and architects. 
To study geometric shape of vertical and horizontal structures we followed two different processes. For vertical structures a series of sections horizontal were performed every $50 \mathrm{~cm}$. On base of this we studied their geometric behaviour. Results obtained showed maximum values of overhang about about $0.22 \mathrm{~m}$ and maximum tilt angle about $1^{\mathrm{g}} .30$.

For horizontal structures has been studied their behaviour respect a horizontal plane. Results obtained showed maximum values enough content and less 1 centimetre while overhang is less than $0^{\mathrm{g}}, 16$.

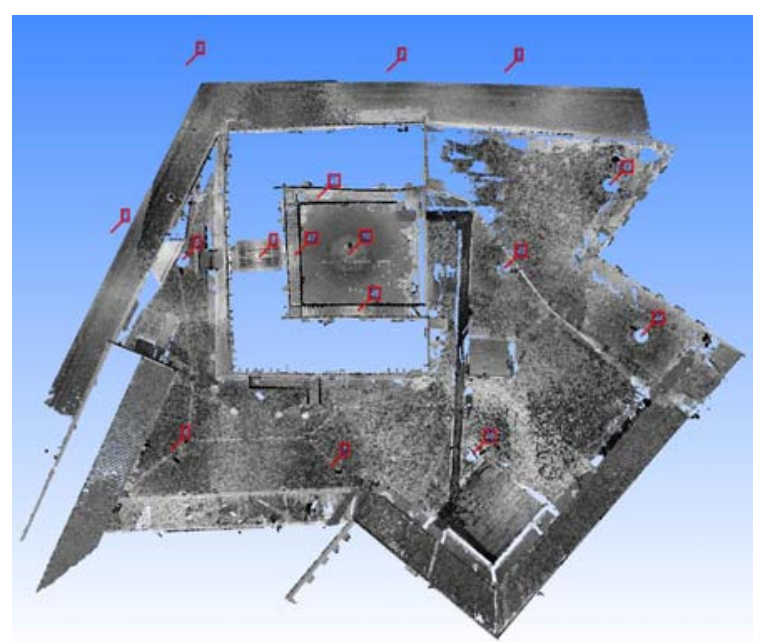

Fig. 7: Point of scans

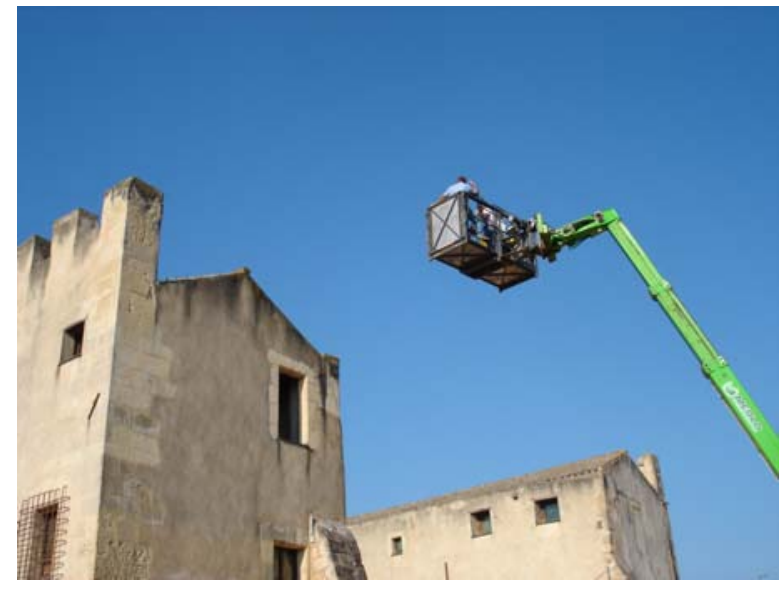

Fig. 8: Lifting platform to roof survey

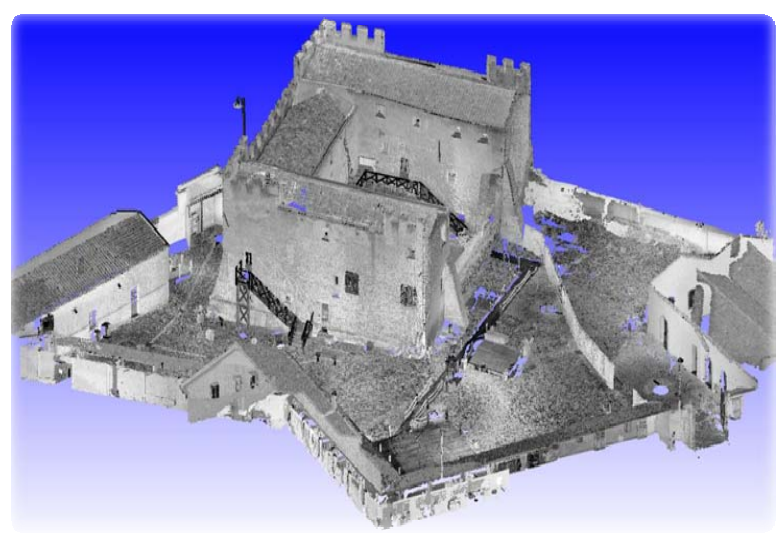

Fig. 9: Sivillier Castle 3D model

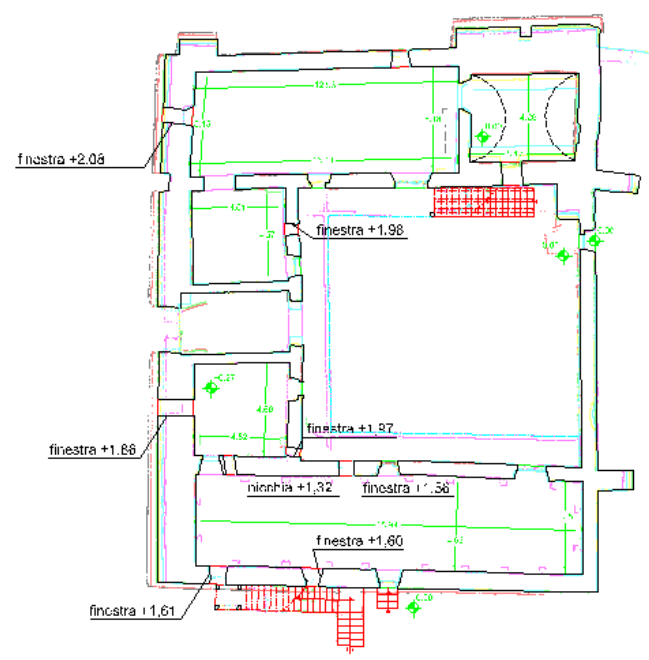

Fig. 10: Plan from point clouds

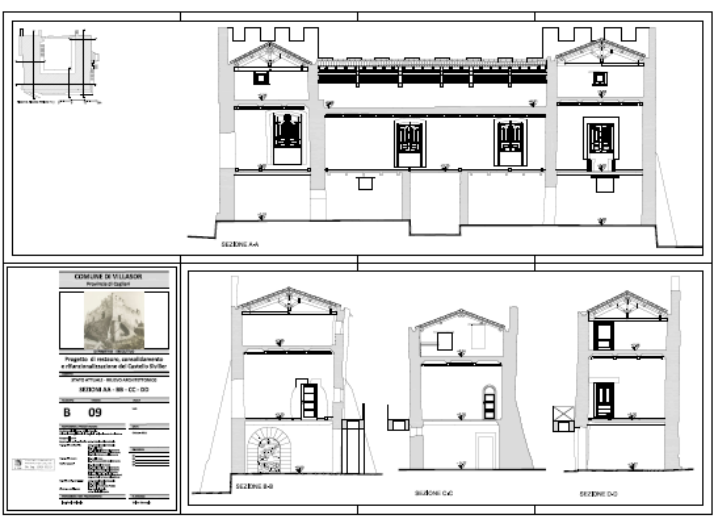

Fig. 11:Vertical sections 


\section{MORES BELL TOWER}

A second case study is survey of Mores Bell Tower. Mores is a small town near Sassari (Sardinia-Italy). The Bell Tower, built in 1871, is the highest bell tower of Sardinia ad it's considered the best neoclassical example in Sardinia. It was built on project of Salvatore Calvia Unali architect, born in Mores in 1822 and died in 1909 in Alghero. He was favourite pupil of Antonelli (architect of the Mole of Turin). The bell tower was completed in two phases up to 1871 , and it represents, as already mentioned, all main elements of neoclassical style with elaborate carvings and stucco on walls of various pink trachyte. On the Bell Tower there are five statues, representing the evangelists and the Redeemer.

In recent time there has been a high degree of degradation of statue placed at top of the bell tower and therefore the Mores municipality is going to study its degradation and causes.

The DICAAR was involved in this study that includes chair of Photogrammetry (Section of Topography) for laser scanner survey, chair of Control of Structures for control structures and chair of Geotechnical for geotechnical investigations. The section of topography has therefore designed and performed laser scanner survey of structure and statues.

Main purposes of this survey were:

1. to define actual height of the bell tower respect to reference field plain;

2. to define geometry of structure and the its deterioration

Survey was divided in following steps:

- Scans planning;

- Scans acquisition;

- Data elaboration;

- Extraction of geometric information;

- Graphic outputs.

Requirements were for an accuracy sufficient for the 1:50 scale. For this scale, considering an graphic error equal to $0.4 \mathrm{~mm}$, requested accuracy is $+/-2 \mathrm{~cm}$.

In order to have a complete survey of the tower bell and statues without empty and a good number of overlapping scans (at least $30 \%$ of them), we made 93 scans with a resolution of $7 \mathrm{~mm}$ (only statues scans were made with resolution of $3 \mathrm{~mm}$ ).

Due to considerable height of bell tower, about $40 \mathrm{~m}$, many scans were made by mounting laser scans on crane boom that leds up scanner to right height. This way allowed us to perform scans of the bell tower and statues at a distance of approximately $10 \mathrm{~m}$ of the portions to be scanned, thus avoiding all the complications of geometric scans made with inclination beam too high.

Also for this case study we used the JRC 3D Reconstructor software for both the data processing and the extraction of the final results.

From the bell tower model we extracted the following graphic outputs:

- Horizontal sections at different heights from the floor

- Vertical sections;

- Internal and external elevations;

- Orthophoto of both the internal and external walls (with GSD $2 \mathrm{~cm}$ ).

Also for this work all graphic outputs were submitted to the manual editing of an expert designer, for completing them and in order to make them understandable by restorers and architects.

From point clouds was possible to determine the height of the bell tower and the statue of the Redeemer, the first is height $36.32 \mathrm{~m}$, while the statue is $3.45 \mathrm{~m}$.

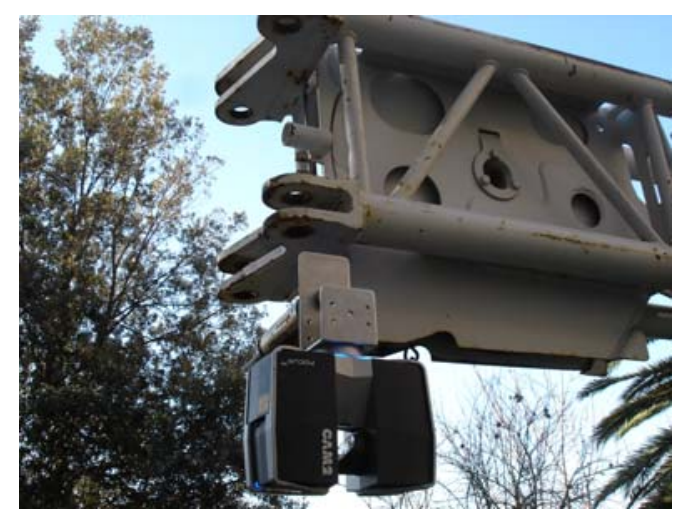

Fig. 12: Laser scanner on the crane boom

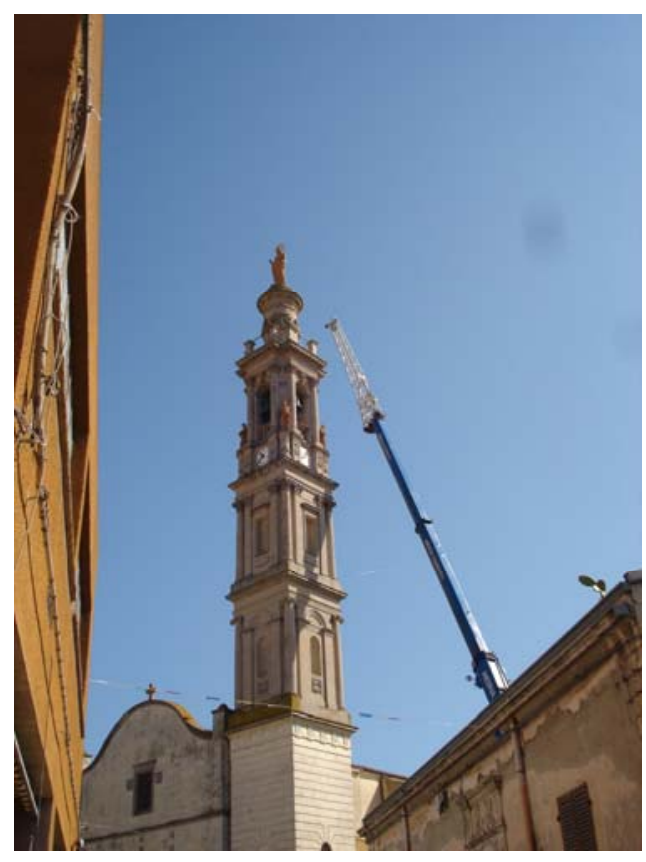

Fig. 13: Laser scanner survey of the Bell Tower

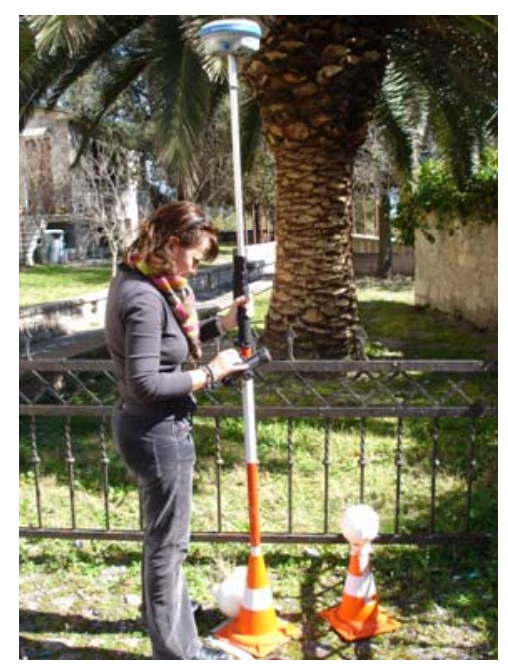

Fig. 14: GPS survey to georeference scans 


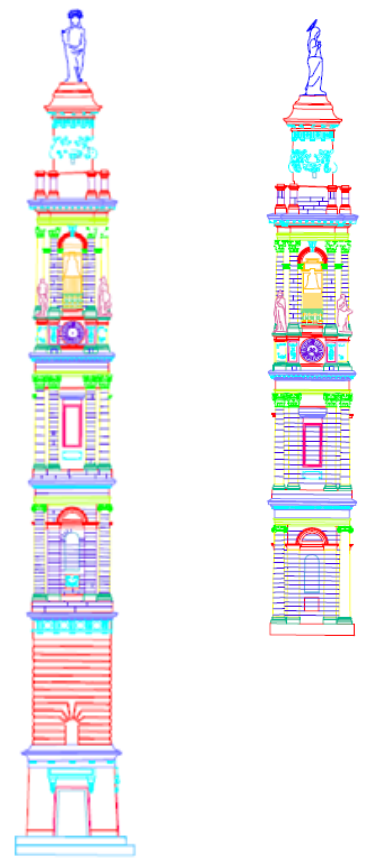

Fig. 15: Bell Tower front elevation
Middle Age Towers. FIG Congress 2010 Facing the Challenges - Building the Capacity Sydney, Australia, 11-16 April 2010

L. Bornaz, F. Rinaudo, 2004. Terrestrial laser scanner data processing. International Archives of Photogrammetry and Remote Sensing, Commission V, ISPRS. XX Congress, Istanbul, Turchia.

Th. Kersten, H. Stenberg, E. Stiemer, 2005. Experiences with terrestrial Laser Scanning foor indoor cultural heritage applications using two different scanning system. Proceedings of the ISPRS working group V/5 "Panoramic Photogrammetry Workshop” Berlin, Germany, 24-25/03/2005 IAPRS, Vol. XXVI, Part 5/W8

\section{CONCLUSION}

In present paper we showed some laser scanner surveys to historical and architectural site.

Cases study presented had different characteristics as well as objectives to be achieved were different. For both it was necessary to obtain documentation of good graphical representation of plans, front elevations and sections.

For the castle Sivillier was also important to study deformation of vertical and horizontal structures, while for the bell tower of Mores was important, also, determine height. In both cases, laser scanner survey has been very important for speed of study of structure geometry both for amount of data and for available measures.

Use of a technique such as a laser scanner for surveying of architectural and historical sites with a complex geometry is displayed, therefore, a useful tool to obtain graphic outputs with high accuracy and navigable and measurable 3D model of surface. It is to highlight a remarkable job of manual editing that needs to be done to get the graphic outputs required by architects.

\section{References}

A. Adami, F. Guerra, P. Vernier, 2007. Laser scanner and architectural accuracy text. XXI International CIPA Symposium, 01-06 October 2007, Athens, Greece.

D. Barber, J. Mills, P. Bryan, 2004. Towards a standard specification for terrestrial laser scanning of cultural heritage one year on. ISPRS, International Archives of Photogrammetry and Remote Sensing, Commission V, ISPRS XX Congress, Istanbul, Turchia.

E. Bertacchini, E. Boni, A. Capra, C. Castagnetti, M. Dubbini, 2010. Terrestrial Laser Scanner for Surveying and Monitoring 